\title{
CROP GROUND COVER FRACTION AND CANOPY CHLOROPHYLL CONTENT MAPPING USING RAPIDEYE IMAGERY
}

\author{
E. Zillmann ${ }^{\mathrm{a}}$, M. Schönert ${ }^{\mathrm{a}}$, H. Lilienthal ${ }^{\mathrm{b}}$, B. Siegmann ${ }^{\mathrm{c}}$, T. Jarmer ${ }^{\mathrm{c}}$, P. Rosso ${ }^{\mathrm{a}}$, H. Weichelt ${ }^{\mathrm{a}}$ \\ a BlackBridge, Dept. of Application Research, 10719 Berlin, Germany - (erik.zillmann@blackbridge.com) \\ b Julius-Kühn-Institute (JKI), Federal Research Centre for Cultivated Plants, 38116 Braunschweig, Germany - \\ (holger.lilienthal@jki.bund.de) \\ 'Institute for Geoinformatics and Remote Sensing, University of Osnabrueck, 49076 Osnabrueck, Germany - (tjarmer@igf.uni- \\ osnabrueck.de)
}

KEY WORDS: Ground Cover, Canopy Chlorophyll Content, RapidEye, Spatial Variability, Precision Agriculture

\begin{abstract}
:
Remote sensing is a suitable tool for estimating the spatial variability of crop canopy characteristics, such as canopy chlorophyll content (CCC) and green ground cover (GGC\%), which are often used for crop productivity analysis and site-specific crop management. Empirical relationships exist between different vegetation indices (VI) and CCC and GGC\% that allow spatial estimation of canopy characteristics from remote sensing imagery. However, the use of VIs is not suitable for an operational production of $\mathrm{CCC}$ and $\mathrm{GGC} \%$ maps due to the limited transferability of derived empirical relationships to other regions. Thus, the operational value of crop status maps derived from remotely sensed data would be much higher if there was no need for reparametrization of the approach for different situations.

This paper reports on the suitability of high-resolution RapidEye data for estimating crop development status of winter wheat over the growing season, and demonstrates two different approaches for mapping CCC and GGC\%, which do not rely on empirical relationships. The final CCC map represents relative differences in CCC, which can be quickly calibrated to field specific conditions using SPAD chlorophyll meter readings at a few points. The prediction model is capable of predicting SPAD readings with an average accuracy of $77 \%$. The GGC\% map provides absolute values at any point in the field. A high $\mathrm{R}^{2}$ value of $80 \%$ was obtained for the relationship between estimated and observed GGC\%. The mean absolute error for each of the two acquisition dates was 5.3\% and $8.7 \%$, respectively.
\end{abstract}

\section{INTRODUCTION}

Remote sensing is a suitable tool for estimating the spatial variability of crop canopy characteristics such as green ground cover (GGC\%) and canopy chlorophyll content (CCC). Both variables are often used for crop productivity analysis and sitespecific crop management. Spatially high-resolution crop growth status information can provide farmers with relevant information e.g. for site-specific application of fertilizer (Scharf and Lory, 2002, Emerine, 2006), growth regulator (Maas et al. 2004), irrigation requirements (Hunsaker et al., 2005, Er-Raki, 2010), and crop productivity analysis (Schulthess et al., 2013). Since field management decisions are often time-critical, an almost real time production and provision of spatially highresolution $\mathrm{CCC}$ and $\mathrm{GGC} \%$ maps is desired.

Leaf chlorophyll absorption in the visible part of the electromagnetic spectrum provides the basis for using remotely sensed reflectance as a tool for the determination of crop development status. Often spectral vegetation indices (VI) are used to derive crop status information. Several studies have proven the existence of empirical relationships between different VIs and both CCC and GGC\%. Even though the normalized difference vegetation index (NDVI) (Rouse et al. 1973 ) is the most commonly used VI, it has the limitation that it tends to saturate when LAI exceeds 2, and it is also strongly influenced by soil background conditions (Baret et al., 1991).

Several other VIs have been proposed for estimating CCC of various crops (Daughtry et al., 2000, Haboudane et al., 2002). In particular, the red-edge region of the spectrum showed strong potential for estimating canopy chlorophyll content. The main advantage of red-edge based indices is their reduced saturation effect due to a lower absorption by the chlorophyll in the red-edge spectral region compared to the red spectrum (Gitelson and Merzlyak, 1996). Thus, red-edge based indices are still sensitive to chlorophyll absorption at higher crop canopy densities. Since CCC varies widely over the growing season and among crops, any VI requires a large dynamic range for chlorophyll estimation. Eitel et al., (2007) have proven the general suitability of the RapidEye red-edge band for CCC estimation in winter wheat.

Accordingly, BlackBridge (as the owner and distributor of RapidEye data) has been using the Normalized Difference RedEdge Index (NDRE) (Barnes et al., 2000), to produce relative chlorophyll maps. Although these maps are known to reflect the variability of $\mathrm{CCC}$ within individual fields, the variable nature of the NDRE-Chlorophyll relationship in different situations, has prevented the establishment of a universal relationship for estimating actual CCC values on the field. This limited transferability of empirical relationships hinders its incorporation into operational production processes.

One option to overcome this limitation is to explore the possibility of establishing a relationship NDRE-CCC on a case by case basis, but with a procedure that is simple enough to be applied by farmers with little effort and previous knowledge. With this goal in mind, in this study a test was performed to determine the accuracy of NDRE maps as predictors of values of CCC when using a set of a few measurements on the ground.

Often VIs used for fractional GGC\% estimation rely on the soil line in the red and near-infrared (NIR) spectral feature space. Richardson and Wiegand (1977) introduced the bare soil line concept to improve the discrimination between bare soil and sparse vegetation cover. In particular the weighted difference vegetation index (WDVI) (Clevers, 1988) and the perpendicular vegetation index (PVI) (Jackson et al., 1980) were successfully 
tested to estimate GGC\% from multi-spectral imagery (Bouman et al., 1992, Schulthess et al., 2013, Maas et al., 2008, Rajan et al., 2009).

Even though the basic concept of the PVI is to reduce the influence of bare soil reflection, this index cannot be considered fully insensitive to soil brightness. Huete et al. (1985) found out that for same amounts of vegetation cover PVI shows lower values on dark soils than on bright soils. Moreover, the initial assumption of an existing "global" soil line encompassing a wide range of soil conditions has been disproved. Soil type specific conditions cause variations in the slope and intercept of the soil line, and consequently influence the value of the particular VI (Huete et al., 1985). Therefore, regional specific soil lines are necessary to enable accurate GGC\% estimation by utilizing soil line based VIs.

Maas et al. (2008) developed a non-empirical and selfcalibrating approach for estimating $\mathrm{GGC} \%$ based on the bare soil line and full canopy point (FCP) reflectance. The FCP is defined as the canopy reflectance in the NIR and the red spectral band at $100 \%$ ground coverage when seen directly from above. With parameters derived from the scatterplot of the NIR vs. the red band values of a particular multi-spectral image, they achieved a GGC $\%$ estimation error below $6 \%$ on average. The operationalization of this approach for the GGC $\%$ map production relies on the automated determination of an adequate soil line and FCP in each particular image, which is highly error-prone without a proper image screening beforehand. The accidental inclusion of urban areas, lakes, clouds and cloud shadows prevents the accurate identification of the soil line (Maas et al., 2008, Xu et al., 2013). Therefore, one of the goals of the study reported here is to find a procedure to improve the automatic extraction of a soil line representative of the area under study.

The identification of the FCP requires the existence of full canopy within the image, which is not guaranteed for acquisitions early and late in the season. Furthermore, leaves transmit and reflect light in the NIR spectrum and absorb only a small fraction. As a result, the NIR reflection for a pixel of full canopy can continue to increase with increasing leaf density. Thus, it is very likely that automatically extracted NIR values are above the normal values of full canopy. To overcome this challenge, the use of an empirical FCP is recommended (Maas et al., 2008).

The aim of this work is to demonstrate the feasibility of the automated generation of relative canopy chlorophyll maps (CCC) and absolute GGC\% maps for individual fields based on RapidEye imagery, with the least amount of manual intervention. The resulting maps were compared to corresponding ground truth measurements of chlorophyll content and GGC\% to assess the accuracy. The produced maps provide information about the spatial variability of crop growth that has potential use in precision agriculture as a means for directed field scouting and variable rate management.

\section{MATERIALS AND METHODS}

\subsection{Study Area}

The study area is located in the federal state of Saxony-Anhalt, Germany $\left(11^{\circ} 54^{\prime} \mathrm{E}, 51^{\circ} 47^{\prime} \mathrm{N}\right)$ in an intensively used agricultural landscape. The region is characterized by Chernozem in conjunction with Cambisols and Luvisols as the predominant soil types of the Loess covered Tertiary plain. The test site is characterized by highly variable spatial soil properties. Within the study area, one winter wheat (Triticum aestivum L) field with a size of 90 ha was selected for the assessment of wheat CCC and GGC\%. The field showed two areas with no vegetation as a result of waterlogging in early spring 2011.

\subsection{Field Measurements and Data Extraction}

Field data were collected close to image acquisition on the $8^{\text {th }}$ of May and $22^{\text {nd }}$ of June 2011. The first campaign was conducted within one day of image acquisition to avoid any distortions of the results due to high daily growth rates at this stage of crop development. The sample locations were defined aiming at covering the entire crop variability within the field as described in Siegmann et al. (2013). A total number of 24 and 18 sample plots were measured at winter wheat's stem elongation and early ripening stage, respectively (Figure 1).

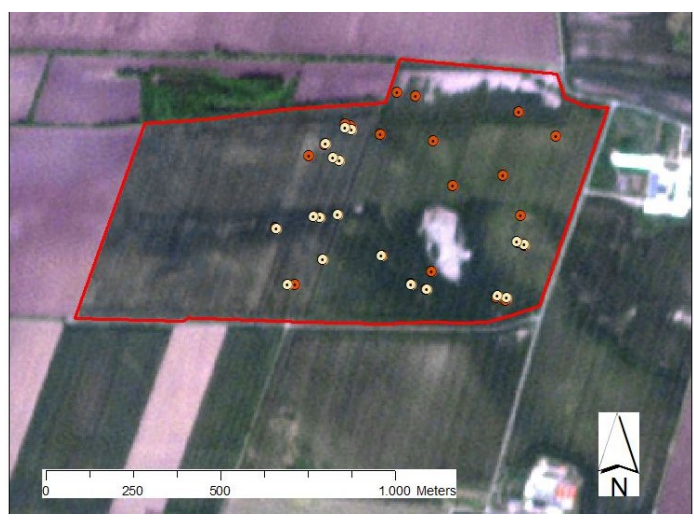

Figure 1. Test site with the sampling locations measured on $8^{\text {th }}$ of May (dark) and $22^{\text {nd }}$ of June 2011 (bright). The image shows the situation on the $7^{\text {th }}$ of May 2011.

\subsubsection{Ground Measurements of Chlorophyll}

Field data collection included leaf area index (Licor LAI$2200^{\circ}$, Delta-T Sunscan ${ }^{\odot}$ ) and leaf chlorophyll meter readings in the upper canopy (Minolta SPAD-502 ${ }^{\circ}$ ). SPAD measurements represent a unit-less relative measurement of leaf chlorophyll content and have been proven to be positively correlated to chlorophyll content of wheat (Reeves et al., 1993) and other crops (Zhu et al., 2012).

Since satellite images represent the spectral reflectance from 3dimensional crop canopies, the SPAD readings at leaf level were also transformed to a 3-dimensional CCC. The CCCSPAD was derived by calculating the product of the corresponding leaf SPAD reading and leaf area index (Gitelson et al., 2005). Samples showed a considerable CCCSPAD range from 18 at minimum to 151 at maximum on the $8^{\text {th }}$ of May 2011 and from 20 at minimum to 240 at maximum on the $22^{\text {nd }}$ of June. The average CCCSPAD from the two dates ranged from 58 to 119 .

\subsubsection{Ground Measurements of Ground Cover}

Photographs of the wheat canopy were taken with a standard digital camera looking downward from a distance of approximately $1.5 \mathrm{~m}$ to allow the estimation of green crop ground cover. Photographs were subject to supervised classification aiming at the objective determination of reference GGC\%. Trimble eCognition Developer $8^{\odot}$ software was used to perform an object-based supervised classification of green vegetation and non-green vegetation. The image was cropped to include only the central portion for the $\mathrm{GGC} \%$ determination to minimize the effects of optical distortions on the plant canopy present near the edges of the image. GGC\% was calculated as 
the area of green vegetation of the resulting polygon shape file divided by the total area of the photograph.

The mean reference GGC $\%$ of the field was $71 \%$ on the $8^{\text {th }}$ of May and $65 \%$ on the $22^{\text {nd }}$ of June 2011. The variability of GGC $\%$ observed was considerably higher in June ranging from $23 \%$ at minimum and $95 \%$ at maximum compared to $42 \%$ at minimum and $96 \%$ at maximum in May.

\subsection{Remote Sensing Data Processing}

\subsubsection{Satellite Imagery}

The RapidEye (RE) satellite system is a constellation of five identical earth observation satellites with the capability to provide large area, multi-spectral images with frequent revisits in high resolution (6.5 $\mathrm{m}$ at nadir). In addition to the blue (440$510 \mathrm{~nm})$, green $(520-590 \mathrm{~nm})$, red $(630-685 \mathrm{~nm})$ and NIR $(760-850 \mathrm{~nm})$ bands, RapidEye has a red-edge band (690$730 \mathrm{~nm}$ ), especially suitable for vegetation analysis. The RapidEye level 3A standard product covers an area of $25 \times 25 \mathrm{~km}$, and is radiometrically calibrated to radiance values (Anderson et al. 2013), ortho-rectified, and resampled to $5 \mathrm{~m}$ spatial resolution. All the images used were calibrated to top of atmosphere reflectance. The two images used (Tile ID $3363006)$ for crop status mapping were acquired on the $7^{\text {th }}$ of May and $27^{\text {th }}$ of June 2011.

\subsubsection{Chlorophyll Mapping}

Since the relationship between canopy chlorophyll and the spectral VI used may vary between crop types or different areas, it is more appropriate to restrict the comparisons to individual crop fields. For this reason, the Chlorophyll Map focuses on differences within single fields, thus providing a relative chlorophyll level scale.

The NDRE was calculated for the entire satellite image (1), as:

$$
\text { NDRE }=(\rho \text { NIR }-\rho R E d g e) /(\rho \text { IR }+\rho R E d g e)
$$

where $\rho N I R$ and $\rho R E d g e$ are the reflectance values of the near infrared and red-edge spectral region.

The NDRE layer obtained was clipped to the test field area and all included pixels were encoded as a relative chlorophyll level index (RCLI) into a $0-100$ grey value scale.

The relative chlorophyll values were calibrated to the field specific conditions by obtaining three ground measurements of CCCSPAD for each of the three chlorophyll level (low, moderate and high) areas previously delineated. A linear regression analysis between the CCCSPAD values and the corresponding relative chlorophyll map values allowed for generating a linear transfer function to be applied to the relative chlorophyll map in order to estimate the spatial distribution of CCC.

\subsubsection{Green Ground Cover Mapping}

Green ground cover (GGC) is defined as the fraction of an area covered with green plant canopy. GGC percent maps are generated based on a modification of the original approach developed by Maas et al. (2008). The required bare soil line slope and intercept were obtained by calculating the arithmetic mean from automatically generated soil lines of a set of multitemporal images using the slightly modified procedure from Fox et al. (2004). Images before and after the main vegetation period were used to guarantee a sufficient number of pixels representing bare soil. The empirical FCP reflectance was determined by averaging the reflectance values from multiple locations within the field known to be more than $90 \%$ covered with vegetation at the time of image acquisition.
The GGC\% (2) was calculated from the ratio of the PVI (3) value to the corresponding full-canopy PVI (PVIFC) value (4) as:

$$
\begin{aligned}
& \text { GGC } \%=\text { PVI } / \text { PVIFC } \\
& \text { where } \\
& \text { PVI }=(\rho N I R-a *(\rho \text { Red }))-b) /\left(1+a^{2}\right)^{0.5} \\
& \text { and } \\
& \left.\operatorname{PVI}_{\mathrm{FC}}=\left(\rho \operatorname{NIR}_{\mathrm{FC}}-\mathrm{a} *\left(\rho \operatorname{Red}_{\mathrm{FC}}\right)\right)-\mathrm{b}\right) /\left(1+\mathrm{a}^{2}\right)^{0.5}
\end{aligned}
$$

in which $\mathrm{a}$ and $\mathrm{b}$ are the slope and the intercept of the bare soil line respectively; and $\rho N I R$ and pred are the reflectance values of the corresponding spectral band.

The final GGC\% map expresses the percentage of ground covered by the crop green foliage $(0 \%$, no green vegetation, and $100 \%$, ground entirely covered with green vegetation).

\subsection{Accuracy Assessment}

The sampling points were buffered with a radius of $10 \mathrm{~m}$ to extract the average estimated CCC (CCC est) and GGC\% values which were then stored in a shape file for subsequent analysis. Linear regression analysis between $\mathrm{CCC}_{\text {est }}$ and ground measured CCCSPAD, as well as between the estimated and observed GGC\% was performed to assess the estimation accuracy, respectively.

\section{RESULTS AND DISCUSSION}

Correlation analysis between the CCCSPAD data obtained during the field sampling campaign and six spectral VIs derived from multi-spectral RapidEye imagery revealed best correlations for those indices incorporating the red-edge reflection (Table 1). The results revealed strong linear correlation between CCCSPAD and NDRE and $\mathrm{CI}_{\text {red-edge }}$ for two different development stages of winter wheat.

Table 1. Correlation coefficient (r) between CCCSPAD of winter wheat and selected vegetation indices $(\mathrm{n}=24$ in May; $\mathrm{n}=18$ in June; level of significance, $p=0.01$ ).

\begin{tabular}{|c|c|c|c|c|c|c|}
\hline Date & NDRE & MCARI & MTVI2 & CIred-edge & OSAVI & NDVI \\
\hline May 2011 & 0.90 & 0.63 & 0.89 & 0.90 & 0.89 & 0.86 \\
\hline
\end{tabular}

\begin{tabular}{|l|c|c|c|c|c|c|}
\hline June 2011 & 0.87 & 0.82 & 0.87 & 0.87 & 0.87 & 0.86 \\
\hline
\end{tabular}

MCARI (Daughtry et al., 2000), MTVI2 (Haboudane et al., 2004),

CIred-edge (Gitelson et al., 2003), OSAVI Rondeaux et al., 1996)

Figure 2 shows the generated RCLI map for the winter wheat field on $7^{\text {th }}$ of May 2011. The dimensionless chlorophyll levels are represented in eight classes of colour tones representing relative differences in chlorophyll content within the field.

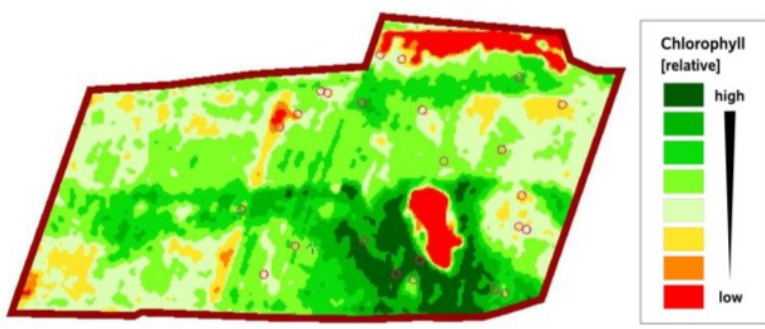

Figure 2. Spatial distribution of classes representing relative chlorophyll level differences in winter wheat on $7^{\text {th }}$ of May 2011. 
This relative map provides accurate information about the spatial variability of $\mathrm{CCC}$ within the field and facilitates directed field scouting to obtain SPAD and LAI measurements in specific areas of the field. These measurements allow for the calibration the RCLI map to field condition specific CCCSPAD values and enables the farmer to make in-season $\mathrm{N}$ fertilization rate decisions and applications.

Three CCC $C_{S P A D}$ measurements corresponding to each of the three classes representing high, moderate, and low relative chlorophyll levels were selected and used to calibrate the relative chlorophyll values to $\mathrm{CCC}_{\mathrm{SPAD}}$ values. The relationship between relative chlorophyll levels and CCCSPAD for both dates is shown in Figure 3-A and Figure 4-A, respectively.

The derived linear transfer function was then used to estimate the spatial variability of CCC based on relative chlorophyll values derived from remotely sensed data. Results of estimating $\mathrm{CCC}_{\text {est }}$ in the described way are plotted in Figure 3-B and Figure 4-B. The least-squares linear regression line fit to the points of $\mathrm{CCC}_{\text {est }}$ vs. ground-based CCCSPAD observations tend to overestimate low CCCSPAD values and underestimate higher $\mathrm{CCC}_{\mathrm{SPAD}}$ values. Based on the prediction, the two outliers (Figure 4-B) should belong to the high CCC group of points but the observed values are significantly lower than that. From an inspection of the sample locations in the satellite images, no particular situation was found to explain these unexpected values. One certain possibility would be a field measurement error.

However, the resulting coefficients of determination $\left(\mathrm{R}^{2}\right)$ indicate that more than $75 \%$ of the total variance among the points can be explained by the models. This strong correlation shows that the procedure applied is able to provide information on the spatial variability of CCC.

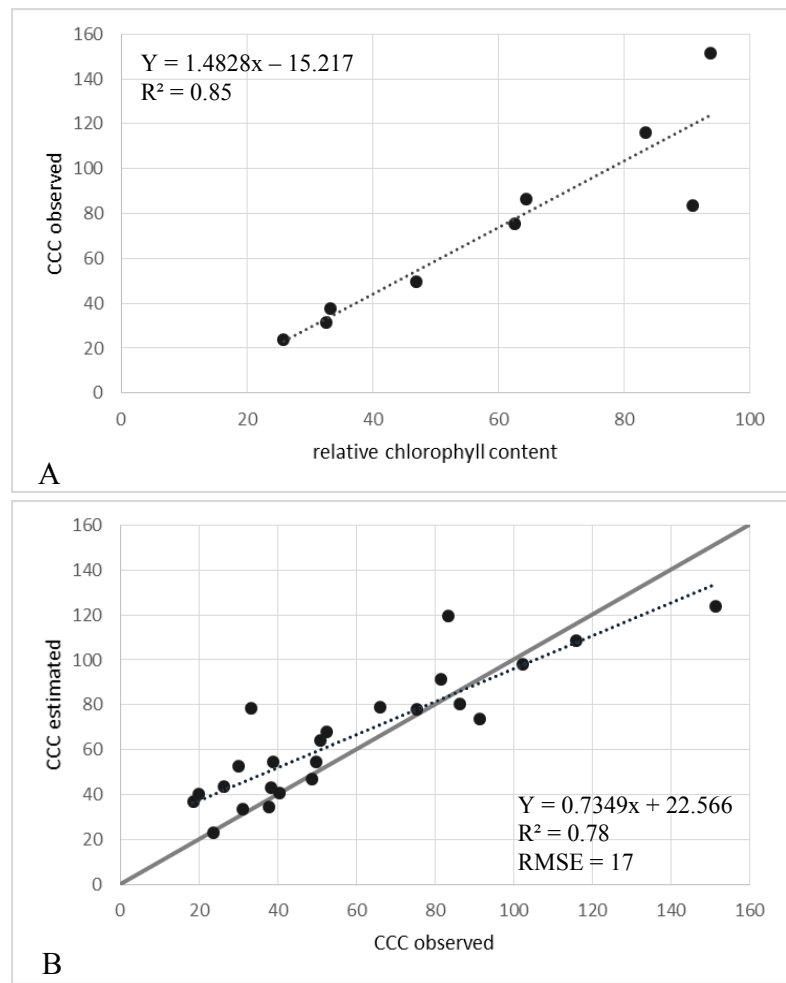

Figure 3. A: Calibration model to turn relative chlorophyll level values into $\mathrm{CCC}_{\mathrm{SPAD}}$ for the May data set. B: Estimated $\mathrm{CCC}_{\text {est }}$ plotted vs. the corresponding observed CCCSPAD measurements on May $7^{\text {th }} 2011$. The solid diagonal line represents the 1:1 line.

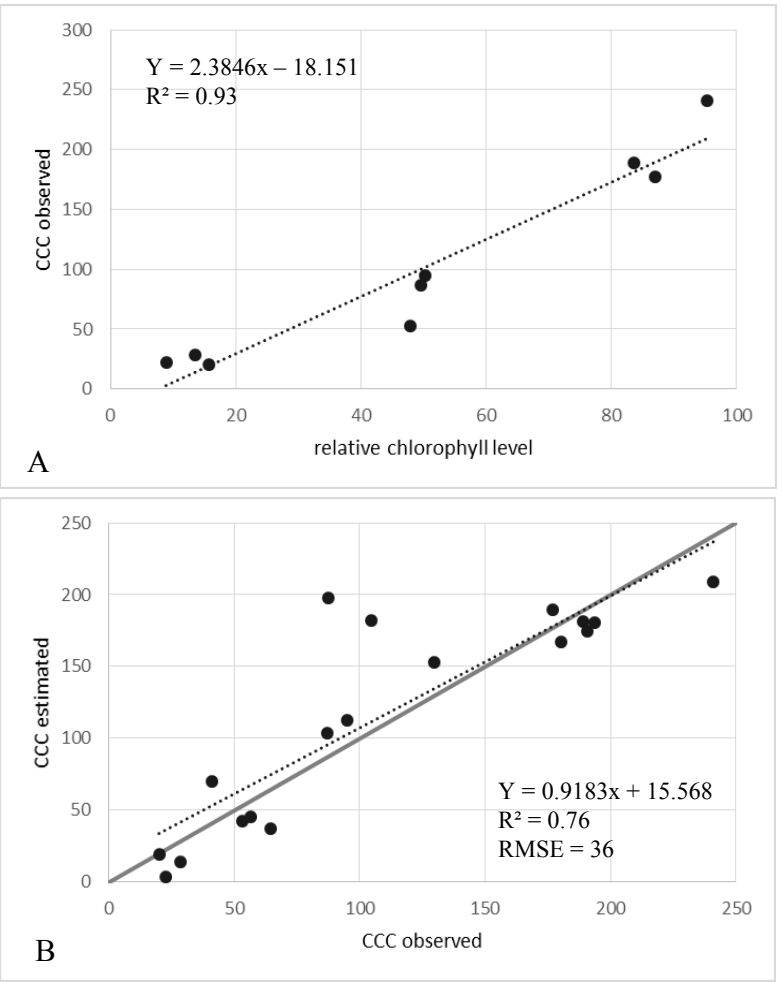

Figure 4. A: Calibration model for the June data set to turn relative chlorophyll level values into CCCSPAD. B: Estimated $\mathrm{CCC}_{\text {est }}$ plotted vs. the corresponding observed CCCSPAD measurements on June $27^{\text {th }} 2011$. The solid diagonal line represents the 1:1 line.

To better evaluate the fit of the model, RMSE, mean absolute error (MAE), and average accuracy (MAE as a percentage of observed mean plus 100) were calculated. On the $8^{\text {th }}$ of May, the prediction accuracy yielded an RMSE of 17 and an MAE of 13 suggesting that on average the estimates of $\mathrm{CCC}_{\text {est }}$ are within 13 SPAD units of their true values. On the $22^{\text {nd }}$ of June the RMSE of 36 and MAE of 25 were slightly higher mainly due to the larger range of values. However, both models were capable of predicting CCCSPAD with an average accuracy of $78 \%$ and $77 \%$.

The final accuracy of the $\mathrm{CCC}_{\text {est }}$ strongly depends on the field measurements used for establishing the calibration model. In case of inadequate measurements, the CCC estimation results will be less accurate. Nevertheless, the results demonstrated that RapidEye imagery is suitable to provide sufficiently accurate relative chlorophyll level maps, which can potentially support site-specific management decisions.

The automatically derived soil line slope (a) and intercept (b) for multi-temporal RapidEye images of the project area are summarized in Table 2. Both parameters are variable over time. Since the area of study is the same in all images, the only remaining reasons for the observed variability could be haze, clouds, cloud shadows, or different non-photosynthetic crop residuals left on the fields. Additionally, an influence of different sensor viewing angles cannot be excluded.

The GGC\% was estimated based on the two RapidEye images acquired on the $7^{\text {th }}$ of May and $27^{\text {th }}$ of June 2011 using equation (2) with the derived average slope of 1.05291 and average intercept of -0.04858 (Table 2) together with the reflectance values for the empirical FCP of winter wheat in the Red $=0.04$ and NIR $=0.4$ spectral band. 
Table 2. Bare soil line characteristics of multi-temporal images and the mean values used for estimating GGC\% from RapidEye images.

\begin{tabular}{|c|c|c|}
\hline Imaging date & Slope (a) & Intercept (b) \\
\hline March 1 ${ }^{\text {st }}, 2011$ & 1.1400 & -0.07887 \\
\hline September $2^{\text {nd }}, 2011$ & 1.0463 & -0.05811 \\
\hline September $24^{\text {th }}, 2011$ & 1.0627 & -0.04996 \\
\hline October $2^{\text {nd }}, 2011$ & 0.95041 & -0.03103 \\
\hline March 26 $6^{\text {nd }}, 2012$ & 0.98531 & -0.02531 \\
\hline $\operatorname{March} 4^{\text {th }}, 2013$ & 1.02156 & -0.03717 \\
\hline March $10^{\text {th }}, 2014$ & 1.17059 & -0.06735 \\
\hline March $29^{\text {th }}, 2014$ & 1.12263 & -0.05741 \\
\hline October $1^{\text {st }}, 2014$ & 0.97676 & -0.03198 \\
\hline Mean & 1.05291 & -0.04858 \\
\hline STDEV & 0.07770 & 0.01836 \\
\hline
\end{tabular}

The results revealed a strong correlation of $r=0.89$ between estimated and observed GGC\% for the sampling locations within the test field. Regression analysis indicated that $80 \%$ of the total variance among the points could be explained by the model (Figure 5) for the pooled data set with an RMSE of 9. The average estimated GGC $\%$ was $68 \%$, which is about $2 \%$ higher than the average observed GGC $\%$. The approach tends to overestimate lower GGC\% and underestimate higher GGC\% values. The derived MAE for the pooled data set was $6.8 \%$ (Table 3). This suggests that estimates of GGC\% using the proposed approach based on an averaged regional soil line and an empirical FCP were on average within $7 \%$ of their true values.

Since field management decisions have to be made based on the actual crop status in the field, the GGC\% estimation accuracy at each particular date is more important than the overall accuracy across the season. The observation date specific accuracy measures are reported in Table 3. For both dates, the calculated MAE values suggest that the GGC\% estimations were on average within $6 \%$ and $9 \%$ of their true values.

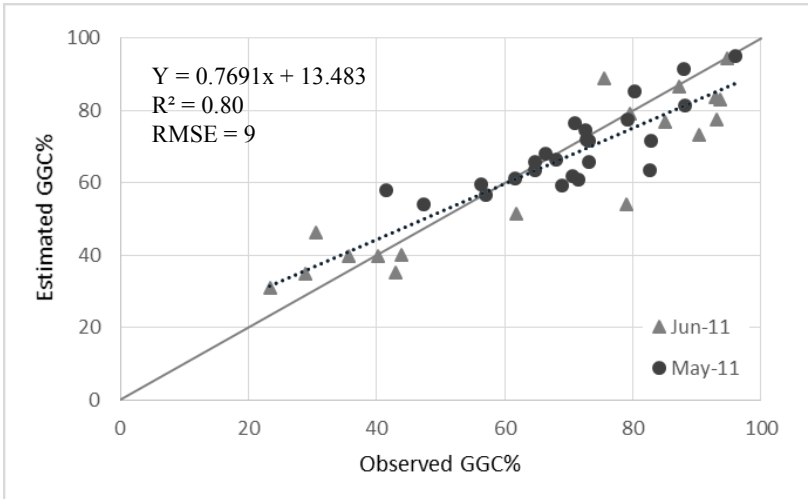

Figure 5. Scatter plot of GGC\% estimated from RapidEye imagery vs. corresponding in-situ measurements of GGC $\%$ for pooled data of the May and June campaign.

Table 3: Accuracy measures for GGC\% estimations based on RapidEye imagery using a regional specific average soil line and an empirical full canopy point reflectance.

\begin{tabular}{|r|c|c|c|}
\hline & $\mathrm{R}^{2}$ & MAE & RMSE \\
\hline May $7^{\text {th }}, 2011$ & 0.61 & 5.3 & 7.3 \\
June 27th 2011 & 0.85 & 8.7 & 10.9 \\
Pooled data & 0.80 & 6.8 & 9.0 \\
\hline
\end{tabular}

Even though the use of an averaged soil line and empirical FCP deprives, to a certain extent, the original GGC\% estimation procedure of the self-calibration capability as its main advantage, the procedure is still able to accurately estimate GGC $\%$.

Figure 6 shows the GGC\% maps produced for the test field based on RapidEye images acquired on the $7^{\text {th }}$ of May and $27^{\text {th }}$ of June 2011. In early May, the GGC\% shows considerable spatial variation in the winter wheat canopy, which might be suitable for variable rate management. The areas with the lowest GGC\% values correspond to the areas affected by waterlogging in early spring. In June, the wheat canopy shows more large-scale variation in $\mathrm{GGC} \%$ compared to May. The larger areas with lower GGC\% represent areas affected by drought-stress-induced abnormally premature ripening due to extreme weather conditions in early summer 2011.
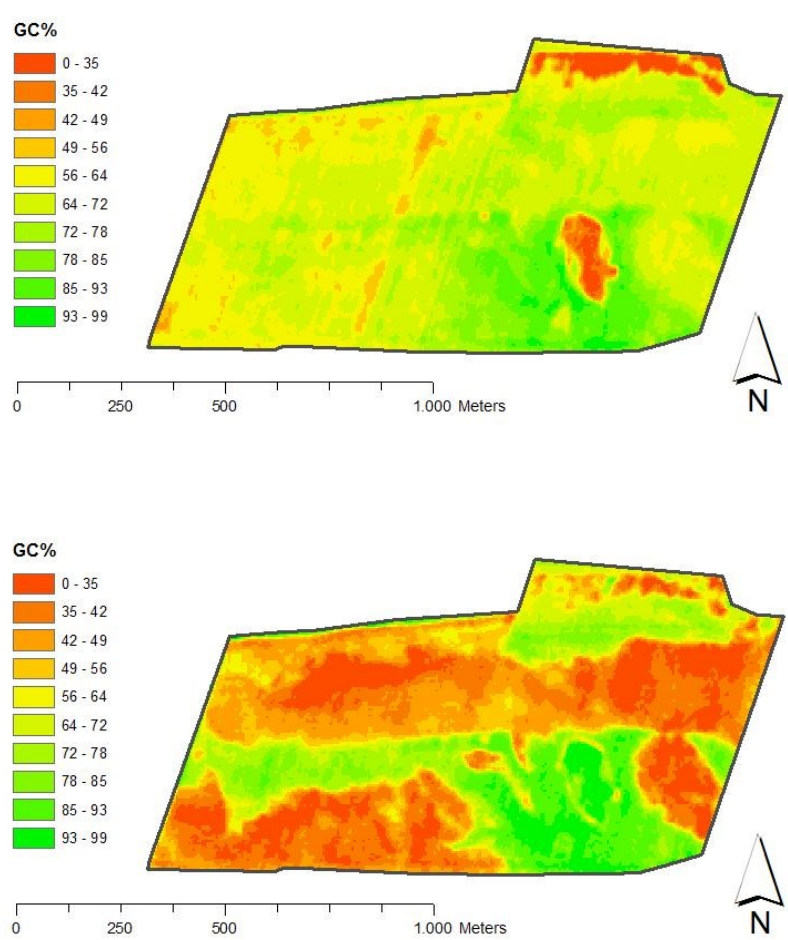

Figure 6. GGC\% maps for winter wheat derived from RapidEye imagery acquired on $7^{\text {th }}$ of May 2011 (top) and on $27^{\text {th }}$ of June 2011 (bottom).

The successful use of a pre-defined, region-specific soil line and FCP parameters instead of determining them directly from the image can probably be attributed to the stability of the sensor calibration over time. Nevertheless, the influence of haze or other atmospheric effects on the GGC\% estimation accuracy have to be investigated further. In this context, focus has to be placed especially on the transferability of the empirical full canopy point reflectance across regions, seasons, and crop types. Since it is known that VIs show different values for crops with planophile and erectrophile leaf canopy architecture, the proposed utilization of an empirical FCP has to be tested on crops other than winter wheat to help reduce estimation errors. 


\section{CONCLUSION}

Results demonstrated that high-resolution RapidEye imagery is suitable for providing accurate spatial information on $\mathrm{CCC}$ and GGC\% during the growing season, and is potentially useful for site-specific crop management.

Relationships between CCCSPAD and red-edge based VIs showed highest correlations for different development stages of winter wheat. Since such empirical relationships are crop type or even cultivar specific, it is almost impossible to achieve reliable and accurate estimations solely from reflectance measurements. A method has been presented that is capable of providing spatially accurate and fast relative chlorophyll level maps, which allow for directed field scouting. The cultivar specific calibration can be realized afterwards at low cost by obtaining a small number of in-situ measurements in different areas representing high, moderate, and low relative chlorophyll content using a portable chlorophyll-meter. This approach is capable of accurately estimating CCCSPAD with an average accuracy of $77 \%$. Such chlorophyll maps provide valuable complementary information for the derivation of site-specific $\mathrm{N}$-fertilizer recommendations. Furthermore, in conjunction with soil fertility and yield maps, chlorophyll level maps can aid in the delineation of site-specific management zones.

The results of this study showed that $\mathrm{GGC} \%$ of winter wheat can be accurately estimated from RapidEye images based on a region-specific bare soil line and an empirical reflectance of crop full canopy. Effective GGC\% prediction of winter wheat across the growing season yielded a coefficient of determination of $\mathrm{R}^{2}=0.8$. On average, the estimated GGC\% values were within $7 \%$ of their true values.

The great operational value of the proposed procedure is that it is does not rely on any empirical relationship. According to Rajan et al (2009) the major advantage of such GGC\% maps is that they provide an absolute measure of crop canopy density at any point in the field, allowing for direct comparison of GGC $\%$ derived from multi-temporal images. Therefore, GGC\% maps enable the monitoring of seasonal crop growth dynamics within individual fields.

RapidEye's short revisit cycle and the red-edge channel make the satellite constellation unique for agricultural monitoring. Its capability for simultaneous acquisitions of crop status information for large areas can greatly reduce the workload for conducting field surveys and the crop analysis necessary to obtain relevant input for precision agriculture.

\section{ACKNOWLEDGEMENT}

The authors wish to express appreciation to the Julius-KühnInstitute (Federal Research Centre for Cultivated Plants in Germany) and the Institute for Geoinformatics and Remote Sensing of the University of Osnabrueck for kindly supplying the field data used in this study, based on the "Hyland" project supported under code 50 EE 1014.

\section{REFERENCES}

Anderson, C., Thiele, M., Brunn, A., 2013. Calibration and validation of the RapidEye constellation. In: Anais XVI Simpósio Brasileiro de Sensoriamento Remoto - SBSR, Foz do Iguaçu, PR, Brasil, 13 a 18 de abril de 2013.

Baret, F., Guyot, G., 1991. Potentials and limits of vegetation indices for LAI and APAR assessment. Rem. Sens. of Environ. $36: 161$.
Barnes, E.M., Clarke, T.R., Richards, E.S., Colaizzi, P.D., Haberland, J.,. Moran, M.S., 2000. Coincident detection of crop water stress, nitrogen status and canopy density using groundbased multispectral data. In: Proc. 5th Int. Conference on Precision Agriculture. Bloomington, MN, USA.

Bouman, B.A.M., van Kasteren, H.W.J., Uenk, D., 1992. Standard relations to estimate ground cover and LAI of agricultural crops from reflectance measurements. Eur. J. Agron. 1, pp. 249-262.

Clevers, J.G.P.W., 1988. The derivation of a simplified reflectance model for the estimation of leaf area index. Rem. Sens. of Environ., 25, pp.53-69.

Daughtry, C.S., Walthall, C.L., Kim, M.S., Brown De Colstoun, E., McMurtrey, J. E., 2000. Estimating corn leaf chlorophyll concentration from leaf and canopy reflectance. Rem. Sens. of Environ., 74, pp. 229-239.

Eitel, J.U.H., Long, D.S., Gessler, P.E.; Smith, A.M.S., 2007. Using in-situ measurements to evaluate the new RapidEye satellite series for prediction of wheat nitrogen status. Int. Journal of Remote Sensing, 28, pp. 1-8.

Emerine, D.M., 2006. Variable and reduced rate nitrogen application based on multispectral aerial imagery and directed field sampling. In: D. Richter (Ed.), Proc. of the 2006 beltwide cotton conference. San Antonio, TX, 3-6 Jan 2006. Memphis, TN, pp. 2128-2131.

Er-Raki, S., Chehbouni, A., Duchemin, B, 2010. Combining Satellite Remote Sensing Data with the FAO-56 Dual Approach for Water Use Mapping. In: Irrigated Wheat Fields of a SemiArid Region. Remote Sens., 2, pp. 375-387.

Fox, G.A., Sabbagh, G.J., Searcy, S.W., Yang, C., 2004. An automated soil line identification routine for remotely sensed images. Soil Sci. Soc. Am. J., 68, pp. 1326-1331.

Gitelson, A.A., Merzlyak, M.N., 1996. Signature analysis of leaf reflectance spectra: Algorithm development for remote sensing of chlorophyll. J. of Plant Phys. 148(3-4), pp. 494-500.

Gitelson, A.A., Merzlyak, M.N., 2003. Relationships between leaf chlorophyll content and spectral reflectance and algorithms for non-destructive chlorophyll assessment in higher plant leaves. J. of Plant Phys., 160(3), pp. 271-282.

Gitelson AA, Vina A., Rundquist, D.C., Ciganda, V., Arkebauer T.J., 2005. Remote estimation of canopy chlorophyll content in crops. Geophys Res Lett; 32.

Haboudane, D., Miller, J.R., Tremblay, N., Zarco-Tejadad, P.J., Dextrazec, L., 2002. Integrated narrow-band vegetation indices for prediction of crop chlorophyll content for application to precision agriculture. Rem. Sens. of Environ., 81, pp. 416-426.

Haboudane, D., Miller, J.R., Pattey, E., Zarco-Tejada, P.J., Strachan, I.B., 2004. Hyperspectral vegetation indices and novel algorithms for predicting green LAI of crop canopies: Modeling and validation in the context of precision agriculture. Rem. Sens. of Environ., 90, pp. 337-352.

Huete, A.R., 1985. Spectral response of a plant canopy with different soil backgrounds. Rem. Sens. of Environ. 17, pp. 3753. 
Hunsaker, D.J., Barnes, E.M., Clarke, T.R., Fitzgerald, G.J., Pinter, P.J., 2005. Cotton irrigation scheduling using remotely sensed and FAO-56 basal crop coefficients. American Society of Agricultural Engineers, St.Joseph, MI.

Jackson, R.D., Pinter, P.J., Paul, J., Reginato, R.J., Robert, J., Idso, S.B., 1980. Hand-held radiometry. Agricultural Reviews and Manuals ARM-W-19. Oakland, California: U.S.

Maas, S.J., Brightbill, J., Hooton, J., 2004. Remote sensing for precision agriculture in the Texas High Plains. In: P. Dugger, D. Richter (Eds.), Proc. of the 2004 beltwide cotton conferences San Antonio, TX, 5-9 Jan 2004. Memphis, TN, pp. 184-187.

Maas, S.J., Rajan, N., 2008. Estimating ground cover of field crops using medium-resolution multispectral satellite imagery. Agron. J. 100, pp. 320-327.

Rajan, N., Maas, S.J., 2009. Mapping crop ground cover using airborne multispectral digital imagery. Precision Agriculture 10(4), pp. 304-318.

Reeves, D.W., Mask, P.L., Wood, C.W., Delano, D.P., 1993. Determination of Wheat Nitrogen Status with Hand-held Chlorophyll Meter: Influence of Management Practices, $J$. Plant Nutrition, 16, pp. 781-796.

Richardson, A.J., Wiegand, C.L., 1977. Distinguishing vegetation from soil background information. Photogrammetric Engineering and Remote Sensing, 43(12), pp. 1541-1552.
Rondeaux, G., Steven, M., Baret, F., 1996. Optimization of Soil adjusted vegetation indices. Rem. Sens. of Environ., 55, pp. 95107.

Rouse, J.W., Haas, R.H., Schell, J.A., Deering, D.W., 1973. Monitoring vegetation systems in the Great Plains with ERTS, Third ERTS Symposium, NASA SP-351 I, pp. 309-317.

Scharf, P.C., Lory, J.A., 2002. Calibrating corn color from aerial photographs to predict sidedress nitrogen need. Contrib. from the Missouri Agric. Exp. Stn. J. Ser. No.13086. Agron. J. 94, pp. 397-404.

Schulthess, U., Timsina, J., Herrera, J. M., McDonald, A., 2013. Mapping field-scale yield gaps for maize: An example from Bangladesh, Field Crops Research, 143(1) pp. 151-156.

Siegmann, B., Jarmer, T., Lilienthal, H., Richter, N., Selige, T., Höfle, B., 2013. Comparison of narrow band vegetation indices and empirical models from hyperspectral remote sensing data for the assessment of wheat nitrogen concentration. In: Proc. 8th EARSeL SIG IS workshop, Nantes, France.

Xu D, Guo X., 2013. A Study of Soil Line Simulation from Landsat Images in Mixed Grassland. Remote Sens., 5(9), pp. 4533-4550.

Zhu, J., Tremblay, N., Liang, Y., 2012. Comparing SPAD and atLEAF values for chlorophyll assessment in crop species, Canadian J. of Soil Science, 92, pp. 645-648. 